\title{
Prognostic value of circulating tumor cells and its association with the expression of cancer stem cells in nasopharyngeal carcinoma patients
}

\author{
Lin LU ${ }^{1,2, *}$, Hao-Wei HUANG ${ }^{1,3, *}$, Huan DU ${ }^{1,4, *}$, Zhi-Xiang LIU ${ }^{1,2}$, Zhi-Qiang ZHA ${ }^{2}$, Pei-Pei WANG ${ }^{1}$, Yong WU ${ }^{1,2}$, Xia LIU ${ }^{1,2}$, Cheng-Yin WENG ${ }^{1,2}$, \\ Xi-Sheng FANG ${ }^{1,2}$, Bao-Xiu LI ${ }^{1,2}$, Hai-Bo MAO ${ }^{1,2}$, Li-Na WANG ${ }^{1,2}$, Xiao-Pai WANG ${ }^{5}$, Ming-Mei GUAN ${ }^{1,2, *}$, Guo-Long LIU ${ }^{1,2, *}$ \\ ${ }^{1}$ Department of Medical Oncology, Guangzhou First People's Hospital, Guangzhou Medical University, Guangzhou, Guangdong, China; \\ ${ }^{2}$ Department of Medical Oncology, Guangzhou First People’s Hospital, School of Medicine, South China University of Technology, Guangzhou, \\ Guangdong, China; ${ }^{3}$ Department of Radiotherapy, Guangzhou Red Cross Hospital, Jinan University, Guangzhou, Guangdong, China; ${ }^{4}$ Sino- \\ pharm Dongfeng General Hospital, Hubei University of Medicine, Shiyan, Hubei, China; ${ }^{5}$ Department of Pathology, Guangzhou First People's \\ Hospital, South China University of Technology, Guangzhou, Guangdong, China
}

*Correspondence: 13808815499@163.com; eyglliu@scut.edu.cn

"Contributed equally to this work.

Received May 21, 2018 / Accepted July 22, 2019

\begin{abstract}
The release of circulating tumor cells (CTCs) into vasculature is an early event in the metastatic process and the detection of CTCs has been widely used clinically. In addition, cancer stem cells (CSCs) are the source of distant metastasis. However, the relationship between CTCs and CSCs in nasopharyngeal carcinoma (NPC) patients was largely unknown. A total of 93 NPC patients were enrolled in this study. The CTCs in the peripheral blood were detected. The expression of ALDH1A1 in the tumor tissues of the corresponding patients was detected using immunohistochemistry (IHC). The prognostic value of CTCs level and the correlation with the expression of ALDH1A1 was evaluated. Data showed that the detection of CTCs was positively correlated with metastasis $(\mathrm{p}<0.001)$. The positive detection of CTCs was also associated with poor overall survival ( $\mathrm{p}=0.025$ ). CTCs $\geq 2$ demonstrated good specificity and sensitivity in predicting distant metastasis, while CTCs $\geq 8$ demonstrated better specificity and sensitivity in predicting prognosis than CTCs $\geq 2$. Furthermore, we found that there was a positive relationship between the detection of CTCs and the expression of ALDH1A1 ( $\mathrm{p}=0.001)$. The prognosis analysis also demonstrated that high ALDH1A1 expression was correlated with poor overall survival ( $\mathrm{p}=0.006)$. Our study demonstrated a positive correlation between the CTCs and the expression of CSCs, both were positively correlated with metastasis and poor prognosis. These results indicated that the CTCs might indirectly reflect the expression of CSCs.
\end{abstract}

Key words: nasopharyngeal carcinoma, circulating tumor cells, cancer stem cells, metastasis, prognosis

Nasopharyngeal carcinoma (NPC), which arises from the epithelial tissue of the pharynx, is characterized by aggressive local behavior and geographic difference [1]. There were 600,000 newly diagnosed cases of NPC each year in China. And the incidence of NPC in South China was higher than in any other part of the country, which made NPC also known as Canton Cancer [2]. Due to the concealing anatomical position, the standard strategies of NPCs are intensitymodulated radiation therapy (IMRT), combined with or without chemotherapy. The application of molecular targeting therapy did improve the life quality of NPC patients. All these strategies make response rates approximately $50-70 \%$ [3]. However, $30-40 \%$ of the patients have a risk of tumor recurrence and metastasis after the first diagnosis. It's generally accepted that the long-term maintenance of cancer stem cells (CSCs) contributed to distant metastasis and tumor relapse
[4]. The CSCs are characterized by self-renewal, chemo-and radio-resistance, and enhanced tumorigenicity $[5,6]$. The identifications of CSCs in solid tumors have confirmed that the existence of CSCs could be used as a prognostic and predicted factor for the disease outcomes $[7,8]$. Thus, it's of great importance to trace the existence and expression of CSCs, which could reflect the treatment response and tumor progression during follow-up. ALDH has been accepted as a CSC marker for NPC tissues and cell lines, which is also an independent prognostic indicator for NPC patients $[9,10]$. NPC cell lines with high ALDH expression exhibited greater abilities to proliferate, resist chemotherapy and radiation, and induce tumor formation [11]. Increased expression of ALDH1A1 in NPC was associated with enhanced invasiveness [12]. Further research demonstrates that overexpression of ALDH1 in the invasive front of primary tumor contrib- 
utes to worse survival of NPC, links closely with epithelialmesenchymal transition (EMT) characteristics and tumor aggressiveness [13]. However, there is a lack of an easy and effective way to detect the existence and expression of CSCs through peripheral blood [14]. Besides developing novel detection technology, the combination with our current liquid biopsy would be an easily accessible and effective way in clinics.

The easily accessible to the peripheral blood makes liquid biopsy an ideal strategy to monitor the tumor development dynamically. CTCs may be considered as seeds of metastasis due to the escape of the cancer cells into the bloodstream from primary and metastatic tumors [15-17]. After going through EMT, dormancy and survival in the bloodstream, CTCs could initiate metastasis. The detection of CTCs has been routinely used in clinics. CTCs were an independent risk factor affecting the prognosis of NPC, and the combined detection of CTCs and EBV-DNA could better predict the prognosis of NPC compared with the single detection of EBV-DNA [18]. The detection of CTCs could serve as a biomarker in monitoring the therapeutic efficacy of treatments for NPC, identifying patients at risk of recurrence [19]. Besides, CTCs are even a novel more sensitive biomarker for minimal residual disease in metastatic NPC than imaging [20].

The current hypothesis is that tumor cells with an intermediate phenotype between epithelial and mesenchymal present the highest plasticity to adapt to secondary sites and constitute CSCs [21]. Moreover, CTCs are viewed as seeds, the source of tumor metastasis [22]. Cancer cells can enter circulation long before a tumor is diagnosed; the majority of cells die and only a minor fraction contains viable metastatic precursors that infiltrate organs and survive as disseminated seeds for eventual relapse $[21,23]$. Thus, we hypothesize there might be a relationship between CSCs and CTCs. Here, we retrospectively studied the relationship between the detection of CTCs in the peripheral blood and the immunostaining of ALDH1A1 in tumor tissues of the same NPC patients. On one way, verifying this hypothesis could help us to know more about the underlying mechanisms of CTCs associated with distant metastasis and tumor relapse. On the other way, this study will provide evidence that CTCs could be used as an ideal biomarker to indirectly assess the expression levels of CSC marker ALDH1A1.

\section{Patients and methods}

Ethical statement. A total of 93 patients were enrolled in the present study. The protocol was approved by the Ethics Committee of Guangzhou First People's Hospital. All the patients included in this study were informed and consents were signed.

Characteristics of patients. There were 93 cases of NPC patients diagnosed between January 2014 and December 2018 in Guangzhou First People's Hospital. There were
63 males and 30 females with a median age of 55.3 (range from 27 to 73). All the patients were staged according to the Chinese 2008 TNM Staging System for Nasopharyngeal Carcinoma. And there were 14 out of 93 cases staged as I+II, and 79 out of 93 cases staged as III+IV.

Detection of circulating tumor cells (CTCs). All the peripheral blood was drawn the day before the first chemotherapy or radiotherapy. A total of $3.2 \mathrm{ml}$ peripheral blood was collected and the CTCs were enriched and detected using Human Blood Cells Deletion Kit (Cyttel). After the lysis of red blood cells, the residue cell pellet was resuspended and subsequently incubated with anti-CD45 monoclonal antibody-coated magnetic beads (catalog no. 11153D, Thermo Fisher Scientific, Inc.) for 20-30 min, followed by the separation of magnetic beads using a magnetic stand (Promega, Madison, WI, USA). Supernatants were subsequently subjected to identification of the enriched CTCs by imFISH, which combines the FISH with chromosome 8 (orange) centromere probes (Abbott Molecular Diagnostics, Des Plaines, IL, USA) and anti-CD45 monoclonal antibody (catalog no. FAB1430T, Cyttel). In brief, the probe CEP8 and specimen were hybridized at $37^{\circ} \mathrm{C}$ for $20-90 \mathrm{~min}$ in a hybridizer (DAKO). Subsequently, they were washed in $50 \%$ formamide at $43^{\circ} \mathrm{C}$ for $15 \mathrm{~min}$, then gradient alcohol. At last, the specimens were incubated with the CD45 conjugated to Alexa Flour 594 (Invitrogen) for $1 \mathrm{~h}$. Afterward, they were washed again with $0.2 \%$ BSA. Finally, the specimens were covered with DAPI which contained Vectashield mounting medium $[24,25]$. Then the results were judged by three different persons under the fluorescence microscope. The criteria were as follows: FISH negative and CD45 positive cells were white blood cells; FISH positive (signal $\geq 3$, no delamination under 40 magnification) and CD45 negative, and the nucleus was single judged as circulating tumor cells. According to the kit instructions, $\geq 2$ circulating tumor cells were judged to be positive for CTCs.

Immunohistochemistry staining (IHC). The paraffinembedded specimens of the primary tumors of the 93 NPC patients were collected and sectioned at $2 \mu \mathrm{m}$ thickness. Slides were baked at $60^{\circ} \mathrm{C}$ for $1 \mathrm{~h}$, deparaffinized with xylene, and rehydrated using an alcohol gradient (100\% alcohol, 95\% alcohol, 80\% alcohol, and 70\% alcohol). The antigens were retrieved using the EDTA solution $(1 \mathrm{mM}$, pH 8.0) as previously described [26]. The tissue slides were then treated with $0.3 \%$ hydrogen peroxide in methanol for 10 min to quench endogenous peroxidase activity. All the slides were incubated with the primary antibody mouse antiALDH1A1 overnight at $4{ }^{\circ} \mathrm{C}$ (Abcam, at a dilution of 1:200). Then slides were washed in phosphate-buffered saline (PBS) and incubated with secondary antibody (Dako EnVision) for $1 \mathrm{~h}$. The signal was developed with a 3,3'diaminobenzidine tetrahydrochloride (DAB) substrate kit (Vector Laboratories, Inc., CA, USA) for 5-10 min. Slides were counterstained with hematoxylin for $2 \mathrm{~min}$ and dehydrated stepwise with 70\%, 80\%, 90\%, 100\% ethanol and xylene. Next, slides were 
mounted with Permount and observed under a light microscope by two independent observers in a blinded manner. Inconsistent data were discussed by the observers until a final agreement was reached. ALDH1A1 staining intensities were rated on a scale of $0-3$ according to the percentage of positive tumor cells $(0,<5 \%$ positive cells; $1,5-25 \% ; 2$, $26-50 \%$; or $3,>50 \%$ ). The expression is very weak for 0 , weak for 1, moderate for 2, and strong for 3. After calculating the scores of ALDH1A1 IHC staining by multiplying the intensity score and the expression scores, which ranged from 0 to 9. ALDH1A1 staining was classified as high expression group for those scores $\geq 4$ and low expression group for those scores $<4[27,28]$. The IHC results were evaluated by two independent investigators blinded to the patients' identity and clinical status. In discrepant cases, a pathologist reviewed the cases and a consensus was reached.

Statistics. All the statistical analysis was performed using SPSS software (version 25.0; SPSS Inc., Chicago, IL, USA) or GraphPad Prism 7 (GraphPad software). Quantitative data were calculated as median (range) or mean \pm SD. $\chi^{2}$-test or Fisher exact test was used to compare the correlations among the levels of CTCs, the expression of ALDH1A1 and clinicopathological parameters of NPC patients. Overall survival was defined as the period between the time of diagnosis and the last follow-up or the death. Kaplan-Meier method was performed to investigate the effect of CTCs or CSCs on the OS. A two-tailed p-value $<0.05$ was considered statistical significance.

\section{Results}

Circulating tumor cells (CTCs) in NPC patients. The counts of CTCs were analyzed in the peripheral blood of 93 NPC patients. The median count of CTCs was 3 (range: 0-51). Representative images of CTCs and corresponding white blood cells (WBCs) are shown in Figure 1A. The CTCs were CEP8+/CD45-/DAPI+ cells while corresponding WBCs were CEP8-/CD45+/DAPI+ cells. There were 68 out of 93 patients detected positive for CTCs while the cut-off value was set as 2 . And the patients were divided into two groups based on a cut-off value was set as 2: negative group and positive group.

We analyzed the relationship between the detection of CTCs and clinicopathological parameters of NPC patients. As shown in Table 1, there was a significant correlation between the detection of CTCs and the metastasis status $(\mathrm{p}<0.001$, Table 1). CTCs were detected significantly more frequently in patients with distant metastasis. However, there were no significant differences between the CTC detection and the age, gender, EBV-DNA, lymph node status, and TNM staging ( $p>0.05$, Table 1). Moreover, we compared the CTC detection in the early-stage (stage I-III) and metastatic stage (stage IV). As shown in Figure 1B, the percentage of CTC detection was much higher in metastatic disease than early-stage $(\mathrm{p}=0.002)$.
Table 1. Relationship between CTCs and clinicopathological features of patients with nasopharyngeal carcinoma (NPC).

\begin{tabular}{|c|c|c|c|c|}
\hline \multirow{2}{*}{ Variables } & \multirow{2}{*}{ Number } & \multicolumn{2}{|c|}{ CTC counts } & \multirow{2}{*}{ p-value } \\
\hline & & Negative & Positive & \\
\hline \multicolumn{5}{|l|}{ Age (years) } \\
\hline$\leq 60$ & $57(61.3 \%)$ & $17(18.3 \%)$ & $40(43.0 \%)$ & 0.426 \\
\hline$>60$ & $36(38.7 \%)$ & $8(8.6 \%)$ & $28(30.1 \%)$ & \\
\hline \multicolumn{5}{|l|}{ Gender } \\
\hline Male & $63(67.7 \%)$ & $20(21.5 \%)$ & $43(46.2 \%)$ & 0.128 \\
\hline Female & $30(32.3 \%)$ & $5(5.4 \%)$ & $25(26.9 \%)$ & \\
\hline \multicolumn{5}{|l|}{ EBV-DNA } \\
\hline Negative & $36(38.7 \%)$ & $10(10.8 \%)$ & $26(27.9 \%)$ & 0.879 \\
\hline Positive & $57(61.3 \%)$ & $15(16.1 \%)$ & $42(45.2 \%)$ & \\
\hline \multicolumn{5}{|l|}{ T stage } \\
\hline $1+2$ & $46(49.5 \%)$ & $18(19.4 \%)$ & $28(30.1 \%)$ & $0.008^{*}$ \\
\hline $3+4$ & 47 (50.5\%) & $7(7.5 \%)$ & $40(43.0 \%)$ & \\
\hline \multicolumn{5}{|c|}{ Lymph nodes } \\
\hline No & $4(4.3 \%)$ & $2(2.15 \%)$ & $2(2.15 \%)$ & 0.292 \\
\hline Yes & 89 (95.7\%) & $23(24.7 \%)$ & $66(71.0 \%)$ & \\
\hline \multicolumn{5}{|l|}{ M status } \\
\hline No & $51(54.8 \%)$ & $23(24.7 \%)$ & $28(30.1 \%)$ & $<0.001^{*}$ \\
\hline Yes & $42(45.2 \%)$ & $2(2.2 \%)$ & $40(43.0 \%)$ & \\
\hline \multicolumn{5}{|l|}{ TNM stage } \\
\hline $\mathrm{I}+\mathrm{II}$ & $14(15.1 \%)$ & $4(4.3 \%)$ & $10(10.8 \%)$ & 0.879 \\
\hline $\mathrm{III}+\mathrm{IV}$ & $79(84.9 \%)$ & $21(22.6 \%)$ & $58(62.3 \%)$ & \\
\hline
\end{tabular}

We further studied the correlation between the detection of CTCs and patients' overall survival. Figure 1C showed the overall survival (OS) curves of NPC patients. The median overall survival time was 16.6 months (range: $5-46.8$, 95\% CI: 30.056-38.046). The median OS time for the CTC negative and the CTC positive group was 24.46 months (95\% CI: 36.810-46.199) and 14.6 months (95\% CI: 25.685-35.336), respectively. There was a negative correlation between the detection of CTCs and OS (Figure 1C, $\mathrm{p}=0.025$ ). The NPC patients with positive CTCs demonstrated a poorer OS. When the cut-off value was set as 8, CTC detection also demonstrated statistical significance in predicting OS (Figure 1D, p <0.001). The specificity and sensitivity of CTC in the evaluation of prognosis and metastasis were investigated using ROC curves. We compared the specificity and sensitivity when the cut-off value was set as 2 or 8 according to similar studies $[29,30]$. As shown in Figure 2A, the AUC value was 0.702 when the cut-off value was 2 , which suggests that the cut-off value set as 2 demonstrated good specificity and sensitivity in predicting the distant metastasis. Whereas, when the cut-off value was set as 8 , it demonstrated better specificity and sensitivity than the cut-off value as 2 in predicting the prognosis (Figure $2 \mathrm{~B}$ ).

The expression and prognosis value of ALDH1A1 in NPC patients. The expression levels of ALDH1A1 in the primary tumor tissues were detected using immunohistochemistry. 60 of 93 patients were classified as a high 
ALDH1A1 expression group. Figures $3 \mathrm{~A}$ and $3 \mathrm{~B}$ showed the representative microphotographs of ALDH1A1 high expression or low expression (Figures 3C, 3D). As shown in Figure 3, ALDH1A1 was mainly located in the invasive front of NPC tissues. The expression of ALDH1A1 was positively correlated with the metastatic status $(\mathrm{p}<0.001$, Table 2$)$. Patients with high ALDH1A1 expression were more likely to develop distant metastasis. Furthermore, the log-rank test
A
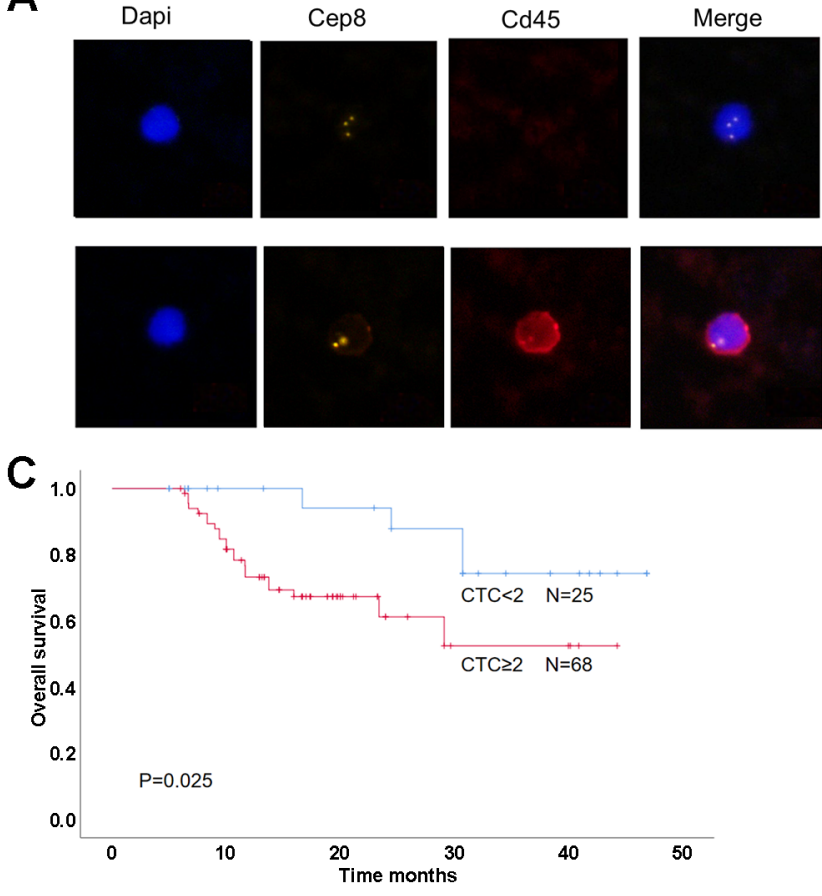

B
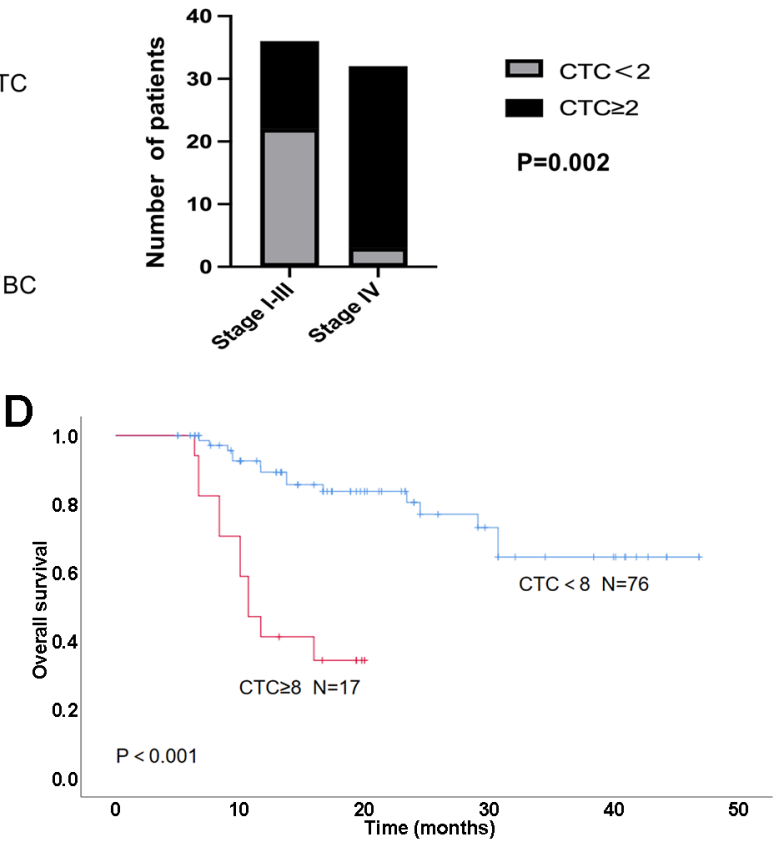

Figure 1. The detection and prognostic value of CTCs in NPC patients. A) Representative images of CTCs. CTCs were CEP8+/CD45-/DAPI+ cells, while corresponding WBCs were CEP8-/CD45+/DAPI+ cells. B) The correlations of CTC between patients with early stage (stage I-III) and advanced stage (stage IV, $\mathrm{p}=\mathbf{0 . 0 0 2}$ ). C) Kaplan-Meier survival curves of NPC patients ( $\mathrm{n}=93$ ). The enumeration of CTCs was correlated with poorer OS. Patients CTCs $\geq 2$ exhibited significantly poorer survival than those CTCs $<2$ (log-rank test: $p=0.025)$. D) Patients with CTCs $\geq 8$ exhibited significantly much poorer survival than those with CTC $<8$ (log-rank test: $\mathrm{p}<0.001)$.
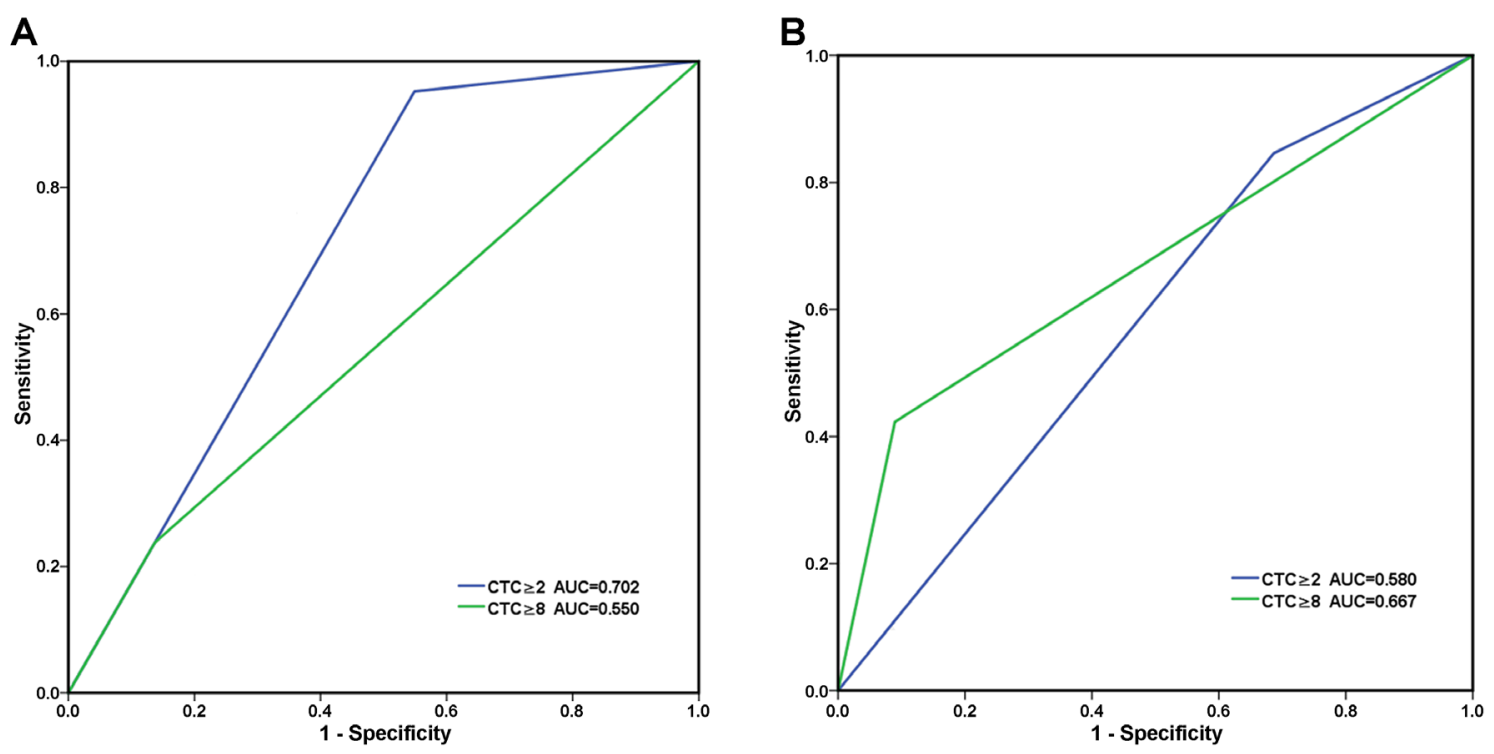

Figure 2. The specificity and sensitivity of CTCs in predicting distant metastasis and prognosis of NPC patients. A) ROC curves demonstrated the specificity and sensitivity of two CTC cut-offs in predicting metastasis. B) ROC analysis of specificity and sensitivity of two CTC cut-offs in predicting overall survival. 

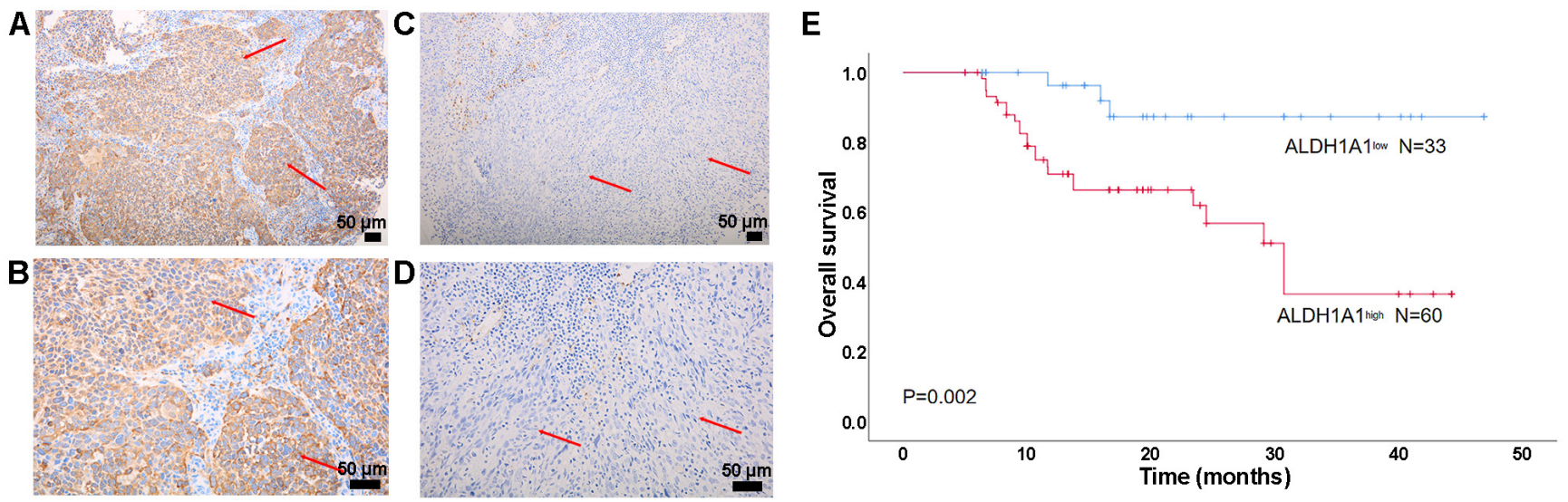

Figure 3. Immunohistochemical detection of ALDH1A1 in nasopharyngeal carcinoma tissues. A, B) High expression of ALDH1A1 in nasopharyngeal carcinoma tissues. C, D) Low expression of ALDH1 A1 in nasopharyngeal carcinoma tissues. The tumor invasive front is highlighted by arrows. E) Kaplan-Meier survival curves of NPC patients $(n=93)$. The high ALDH1A1 expression was correlated with poorer overall survival (log-rank test: $\mathrm{p}=0.002$ ). Original magnification: A, C 20x; B, D 40×.

demonstrated that the high ALDH1A1 expression was correlated with poor OS (Figure 3E, $\mathrm{p}=0.002$ ).

Relationship between the expression of ALDH1A1 and the counts of CTCs. The chi-square test was used to assess the relationship between the expression of CTCs and ALDH1A1. As shown in Table 3, there was a positive correlation between the expression of CTCs and ALDH1A1 ( $\mathrm{p}=0.001)$. Increased expression of ALDH1A1 was more commonly observed in patients with positive CTCs detection.

Further univariate analysis demonstrated that CTCs $\geq 2$ $(\mathrm{p}=0.032)$, CTCs $\geq 8(\mathrm{p}<0.001)$, and ALDH1A $1^{\text {high }}(\mathrm{p}=0.006)$ expression was significantly associated with an OS (Table 4). While multivariate analysis shows only CTCs $\geq 8$ ( $\mathrm{p}=0.001$ ) and ALDH1A1 expression ( $\mathrm{p}=0.006)$ significantly associated with OS (Table 5).

\section{Discussion}

Most of the NPC patients were diagnosed at an advanced stage [31]. Even the overall 5-year survival rate was about $50-70 \%$ [3], there are still more possibilities to develop distant metastasis or relapse. A biomarker that could predict the tumor onset prior to the imaging diagnosis and the clinical symptoms will benefit most of cancer patients. CTCs could be detected in the early stages of tumor development $[32,33]$. And CTC detection has been widely used in clinics, which makes it a promising biomarker in predicting OS and monitoring the treatment response and disease progression. CTCs were generally viewed as an intermediate stage of metastasis [17]. Zhao et al. found the CTC status was correlated with distant metastasis of pancreatic cancer patients. The increased quantification of CTCs was correlated with decreased OS and progression-free survival [34]. Similarly, our study demonstrated that the positive detection of CTCs was significantly correlated with metastasis and poor
Table 2. Relationship between ALDH1A1 expression and clinicopathological features of patients with NPC.

\begin{tabular}{|c|c|c|c|c|}
\hline \multirow{2}{*}{ Variables } & \multirow{2}{*}{ Number } & \multicolumn{2}{|c|}{ ALDH1A1 } & \multirow{2}{*}{ p-value } \\
\hline & & Low group & High group & \\
\hline Age (years) & & & & 0.435 \\
\hline$\leq 60$ & $57(61.3 \%)$ & $22(23.7 \%)$ & $35(37.6 \%)$ & \\
\hline$>60$ & $36(38.7 \%)$ & $11(11.8 \%)$ & $25(26.9 \%)$ & \\
\hline Gender & & & & 0.535 \\
\hline Male & $63(67.7 \%)$ & $21(22.6 \%)$ & $42(45.2 \%)$ & \\
\hline Female & $30(32.3 \%)$ & $12(12.9 \%)$ & $18(19.3 \%)$ & \\
\hline EBV-DNA & & & & 0.921 \\
\hline Negative & $36(38.7 \%)$ & $13(14.0 \%)$ & $23(24.7 \%)$ & \\
\hline Positive & $57(61.3 \%)$ & $20(21.5 \%)$ & $37(39.8 \%)$ & \\
\hline T stage & & & & 0.113 \\
\hline $1+2$ & $46(49.5 \%)$ & $20(21.4 \%)$ & $26(28.0 \%)$ & \\
\hline $3+4$ & 47 (50.5\%) & $13(14.0 \%)$ & $34(36.6 \%)$ & \\
\hline Lymph nodes & & & & 0.126 \\
\hline No & $4(4.3 \%)$ & $3(3.2 \%)$ & $1(1.1 \%)$ & \\
\hline Yes & $89(95.7 \%)$ & $30(32.3 \%)$ & $59(63.4 \%)$ & \\
\hline M status & & & & $<0.001^{*}$ \\
\hline No & $51(54.8 \%)$ & 27 (29.0\%) & $24(25.8 \%)$ & \\
\hline Yes & $42(45.2 \%)$ & $6(6.5 \%)$ & $36(38.7 \%)$ & \\
\hline TNM stage & & & & $0.002^{*}$ \\
\hline $\mathrm{I}+\mathrm{II}$ & $14(15.1 \%)$ & $10(10.8 \%)$ & $4(4.3 \%)$ & \\
\hline III+IV & $79(84.9 \%)$ & $23(24.7 \%)$ & $56(60.2 \%)$ & \\
\hline
\end{tabular}

Note: *statistically significant $\mathrm{p}<0.05$

Table 3. The relationship between the enumeration of CTCs and the expression of ALDH1A1.

\begin{tabular}{lccccc}
\hline \multirow{2}{*}{ CTCs } & \multirow{2}{*}{$\mathbf{N}$} & \multicolumn{2}{c}{ ALDH1A1 expression } & \multirow{2}{*}{$\mathcal{X}^{2}$} & \multirow{2}{*}{ p-value } \\
\cline { 3 - 4 } & & High expression & Low expression & & \\
\hline Negative & 25 & $9(9.7 \%)$ & $16(17.2 \%)$ & 12.145 & $0.001^{*}$ \\
Positive & 68 & $51(54.8 \%)$ & $17(18.3 \%)$ & & \\
\hline
\end{tabular}

Note: * statistically significant $\mathrm{p}<0.05$ 
Table 4. Univariate analyses of variables associated with overall survival of NPC patients.

\begin{tabular}{lccc}
\hline \multirow{2}{*}{ Variables } & \multicolumn{3}{c}{ Univariate analysis } \\
\cline { 2 - 4 } & HR & $\mathbf{9 5 \% ~ C I ~}$ & p-value \\
\hline Age $(>60$ vs. $\leq 60)$ & 2.469 & $1.137-5.362$ & $0.022^{*}$ \\
Gender (male vs. female) & 0.823 & $0.364-1.862$ & 0.641 \\
EBV-DNA (negative vs. positive) & 1.704 & $0.738-3.932$ & 0.199 \\
T stage (3+4 vs. 1+2) & 1.069 & $0.495-2.310$ & 0.865 \\
N status (yes vs. no) & 21.582 & $0.006-83765.557$ & 0.466 \\
M status (yes vs. no) & 1.381 & $0.411-4.641$ & 0.602 \\
CTC ( $\geq 2$ vs. $<2)$ & 3.443 & $1.110-10.679$ & $0.032^{*}$ \\
CTC $(\geq 8$ vs. $<8)$ & 6.367 & $2.687-15.087$ & $<0.001^{*}$ \\
ALDH1A1 (high vs. low) & 5.444 & $1.624-18.242$ & $0.006^{*}$ \\
\hline
\end{tabular}

Note: * statistically significant $\mathrm{p}<0.05$

Table 5. Multivariate analyses of variables associated with overall survival of NPC patients.

\begin{tabular}{lccc}
\hline \multirow{2}{*}{ Variables } & \multicolumn{3}{c}{ Multivariate analysis } \\
\cline { 2 - 4 } & HR & 95\% CI & p-value \\
\hline Age (>60 vs. $\leq 60)$ & 0.432 & $0.182-1.023$ & 0.056 \\
Gender (male vs. female) & 1.645 & $0.673-4.018$ & 0.275 \\
EBV-DNA (negative vs. positive) & 0.698 & $0.290-1.677$ & 0.421 \\
T stage (3+4 vs. 1+2) & 2.116 & $0.837-5.348$ & 0.113 \\
N status (yes vs. no) & 0.000 & 0.000 & 0.979 \\
M status (yes vs. no) & 1.705 & $0.665-4.373$ & 0.267 \\
CTC ( $\geq 2$ vs. $<2)$ & 0.422 & $0.107-1.669$ & 0.219 \\
CTC ( $\geq 8$ vs. $<8)$ & 0.218 & $0.086-0.551$ & $0.001^{*}$ \\
ALDH1A1 (high vs. low) & 0.157 & $0.042-0.589$ & $0.006^{*}$ \\
\hline Not ${ }^{*}$ statisticaly sign
\end{tabular}

Note: * statistically significant $\mathrm{p}<0.05$

prognosis in NPC patients. Patients with positive CTCs were more likely to develop distant metastasis. In the previous studies, the cut-off value of $\geq 2$ CTCs $/ 3.2 \mathrm{ml}$ blood was used to define CTC positivity [35], whereas in a study reported by Zhang et al. the cut-off of $\geq 8$ CTCs $/ 3.2 \mathrm{ml}$ could more significantly predict worse patient outcome among different cut-off values tested [29]. In the present research, we further analyzed CTCs' correlation with distant metastasis and OS when the cut-off point was set as 2 or 8 cells. ROC analysis shows that while the cut-off value was set as 2, CTCs demonstrated good specificity and sensitivity in predicting distant metastasis. Whereas, when the cut-off value was set as 8, it demonstrated better specificity and sensitivity than the cut-off value as 2 in predicting the prognosis. Our univariate analysis demonstrated that both CTCs $\geq 2$ and CTCs $\geq 8$ could be viewed as a prognostic factor. While our multivariate analysis demonstrated only CTCs $\geq 8$ showed a significant correlation with OS. More patients should be enrolled in future research.

There were various CTC markers for NPC, including CD45-CK/EpCAM+ [36] and CD45-CEP8+. Most of the studies revealed that CTC was characterized by CD45-
CEP8+cells in NPC [37-39]. In this study, CTCs were detected using immunostaining of DAPI, CD45, and CEP8. Cells stained as CEP8+/CD45-/DAPI+ were considered as CTCs. Similar studies have verified that CEP8+/CD45-/ DAPI+ CTCs demonstrated good sensitivity and specificity in the diagnosis and prognosis of cancer patients, including neuroblastoma [40], ampullary carcinoma [25], lung cancer [29], pancreatic cancer [41, 42].

CTCs have a clinical value in monitoring the outcome of primary and metastatic diseases [43]. Changes in CTC quantification during treatment can reflect prognostic significance [44]. Nowadays many studies have raised the idea that there was a close relationship between CTCs and CSCs. Some studies have verified that CTCs hold stem cell-like properties, including self-renewal, chemoradioresistance, tumor initiation, and distant metastasis [45, 46]. Papadaki et al. identified a subpopulation of breast cancer cells co-expressing $\mathrm{ALDH}^{+}$, Cytokeratin ${ }^{+} \mathrm{CTCs}$, and TWIST $1^{+}$EMT markers and defined them as $\mathrm{CSC}^{+} /$partial$\mathrm{EMT}^{+} \mathrm{CTCs}$. And this subpopulation of CTCs demonstrated chemoresistance and was associated with distant metastasis and unfavorable prognosis in breast cancer patients [47]. In addition, ALDH1A1 has been accepted as a reliable prognostic and CSC biomarker in NPC patients $[9,13]$. The ALDH1A1 $1^{\text {high }}$ cells were mainly located in the invasive front of nasopharyngeal carcinoma and closely correlated with the EMT process [13]. Pereira-Veiga et al. found that CTCs with an EpCAM $^{\text {high }}$ IMM $^{\text {low }}$ ALDH1A $11^{\text {high }}$ signature demonstrated poor overall survival and diseases-free survival in breast cancer patients [48]. Another study conducted by Aktas et al. found that there was about 69\% CTCs expressed ALDH [49]. Here, in this study, we detected the quantification of CTCs in the peripheral blood, as well as the expression of ALDH1A1 in the tumor tissues of corresponding NPC patients. There was a positive correlation between the counts of CTCs and the immunostaining scores of ALDH1A1. Since the expression levels of CSC marker ALDH1A1 in the tumor tissue were much harder to obtain than the detection of CTC in the peripheral blood. The close relationship between CTCs and CSCs makes CTCs an indirect way to reflect the expression of CSCs.

In conclusion, our study demonstrated that both the detection of CTCs and the expression of CSCs were correlated with metastasis and prognosis. There was a positive correlation between CTCs and the expression of CSCs, which makes CTC detection an ideal biomarker to indirectly reflect the expression of CSCs.

Acknowledgments: This research was funded by the Natural Science Foundation of Guangdong Province, China (No. 2021A1515011113), Guangzhou Science and Technology Program (No. 201904010427), Guangzhou General Science and technology project of Health and Family Planning (grant number 20201A011007), and the Science Foundation of Guangzhou First People's Hospital (No. M2019006 and M2019011). 


\section{References}

[1] MCDERMOTT AL, DUTT SN, WATKINSON JC. The aetiology of nasopharyngeal carcinoma. Clin Otolaryngol Allied Sci 2001; 26: 82-92. https://doi.org/10.1046/j.13652273.2001.00449.x

[2] CHEN W, ZHENG R, BAADE PD, ZHANG S, ZENG H et al. Cancer statistics in China, 2015. CA Cancer J Clin 2016; 66: 115-132. https://doi.org/10.3322/caac.21338

[3] BENSOUDA Y, KAIKANI W, AHBEDDOU N, RAHHALI $\mathrm{R}, \mathrm{JABRI} \mathrm{M}$ et al. Treatment for metastatic nasopharyngeal carcinoma. Eur Ann Otorhinolaryngol Head Neck Dis 2011; 128: 79-85. https://doi.org/10.1016/j.anorl.2010.10.003

[4] PEITZSCH C, TYUTYUNNYKOVA A, PANTEL K, DUBROVSKA A. Cancer stem cells: The root of tumor recurrence and metastases. Semin Cancer Biol 2017; 44: 10-24. https://doi.org/10.1016/j.semcancer.2017.02.011

[5] BADRINATH N, YOO SY. Recent Advances in Cancer Stem Cell-Targeted Immunotherapy. Cancers (Basel) 2019; 11: 310. https://doi.org/10.3390/cancers11030310

[6] NING N, PAN Q, ZHENG F, TEITZ-TENNENBAUM S, EGENTI $M$ et al. Cancer stem cell vaccination confers significant antitumor immunity. Cancer Res 2012; 72: 1853-1864. https://doi.org/10.1158/0008-5472.CAN-11-1400

[7] YANG L, REN Y, YU X, QIAN F, BIAN BSJ et al. ALDH1A1 defines invasive cancer stem-like cells and predicts poor prognosis in patients with esophageal squamous cell carcinoma. Mod Pathol 2014; 27: 775-783. https://doi.org/10.1038/ modpathol.2013.189

[8] XU J, MÜLLER S, NANNAPANENI S, PAN L, WANG Y et al. Comparison of quantum dot technology with conventional immunohistochemistry in examining aldehyde dehydrogenase $1 \mathrm{~A} 1$ as a potential biomarker for lymph node metastasis of head and neck cancer. Eur J Cancer 2012; 48: 1682-1691. https://doi.org/10.1016/j.ejca.2011.12.029

[9] WU A, LUO W, ZHANG Q, YANG Z, ZHANG G et al. Aldehyde dehydrogenase 1 , a functional marker for identifying cancer stem cells in human nasopharyngeal carcinoma. Cancer Lett 2013; 330: 181-189. https://doi.org/10.1016/j. canlet.2012.11.046

[10] WANG S, MA N, ZHAO W, MIDORIKAWA K, KAWANISHI $S$ et al. Inflammation-Related DNA Damage and Cancer Stem Cell Markers in Nasopharyngeal Carcinoma. Mediators Inflamm 2016; 2016: 9343460. https://doi. org/10.1155/2016/9343460

[11] YU F, SIM ACN, LI C, LI Y, ZHAO X et al. Identification of a subpopulation of nasopharyngeal carcinoma cells with cancer stem-like cell properties by high aldehyde dehydrogenase activity. Laryngoscope 2013; 123: 1903-1911. https:// doi.org/10.1002/lary.24003

[12] HOU W, HE W, LI Y, MA R, WANG Z et al. Increased expression of aldehyde dehydrogenase $1 \mathrm{Al}$ in nasopharyngeal carcinoma is associated with enhanced invasiveness. Eur Arch Otorhinolaryngol 2014; 271: 171-179. https://doi. org/10.1007/s00405-013-2517-x

[13] LUO WR, YAO KT. Cancer stem cell characteristics, ALDH1 expression in the invasive front of nasopharyngeal carcinoma. Virchows Arch 2014; 464: 35-43. https://doi. org/10.1007/s00428-013-1508-Z
[14] HOE SLL, TAN LP, JAMAL J, PEH SC, NG CC et al. Evaluation of stem-like side population cells in a recurrent nasopharyngeal carcinoma cell line. Cancer Cell Int 2014; 14: 101. https://doi.org/10.1186/s12935-014-0101-0

[15] CHAFFER CL, WEINBERG RA. A perspective on cancer cell metastasis. Science 2011; 331: 1559-1564. https://doi. org/10.1126/science. 1203543

[16] PANTEL K, SPEICHER MR. The biology of circulating tumor cells. Oncogene 2016; 35: 1216-1224. https://doi. org/10.1038/onc.2015.192

[17] MICALIZZI DS, MAHESWARAN S, HABER DA. A conduit to metastasis: circulating tumor cell biology. Genes Dev 2017; 31: 1827-1840. https://doi.org/10.1101/ gad.305805.117

[18] OU G, XING S, LI J, ZHANG L, CHEN S. Circulating tumor cells: a valuable marker of poor prognosis for advanced nasopharyngeal carcinoma. Mol Med 2019; 25: 50. https://doi. org/10.1186/s10020-019-0112-3

[19] WEN Z, LI Z, YONG P, LIANG D, XIE D et al. Detection and clinical significance of circulating tumor cells in patients with nasopharyngeal carcinoma. Oncol Lett 2019; 18: 2537 2547. https://doi.org/10.3892/ol.2019.10560

[20] KO JMY, VARDHANABHUTI V, NG WT, LAM KO, NGAN RKC et al. Clinical utility of serial analysis of circulating tumour cells for detection of minimal residual disease of metastatic nasopharyngeal carcinoma. Br J Cancer 2020; 123: 114-125. https://doi.org/10.1038/s41416-020-0871-1

[21] TAM WL, WEINBERG RA. The epigenetics of epithelialmesenchymal plasticity in cancer. Nat Med 2013; 19: 14381449. https://doi.org/10.1038/nm.3336

[22] GUPTA GP, MASSAGUE J. Cancer metastasis: building a framework. Cell 2006; 127: 679-695. https://doi. org/10.1016/j.cell.2006.11.001

[23] NGUYEN DX, BOS PD, MASSAGUÉ J. Metastasis: from dissemination to organ-specific colonization. Nat Rev Cancer 2009; 9: 274-284. https://doi.org/10.1038/nrc2622

[24] TONG B, XU Y, ZHAO J, CHEN M, XING J et al. Prognostic significance of circulating tumor cells in non-small cell lung cancer patients undergoing chemotherapy. Oncotarget 2017; 8: 86615-86624. https://doi.org/10.18632/oncotarget.21255

[25] SUN B, LIU H, WANG S, XIANG J, LIU X. Prognostic impact of circulating tumor cells in patients with ampullary cancer. J Cell Physiol 2018; 233: 5014-5022. https://doi. org/10.1002/jcp.26353

[26] LU L, PAN K, ZHENG HX, LI JJ, QIU HJ et al. IL-17A promotes immune cell recruitment in human esophageal cancers and the infiltrating dendritic cells represent a positive prognostic marker for patient survival. J Immunother 2013; 36: 451-458. https://doi.org/10.1097/CJI.0b013e3182a802cf

[27] WANG W, LV L, PAN K, ZHANG Y, ZHAO JJ et al. Reduced expression of transcription factor AP-2alpha is associated with gastric adenocarcinoma prognosis. PLoS One 2011; 6: e24897. https://doi.org/10.1371/journal.pone.0024897

[28] LU L, DU H, HUANG H, WANG C, WANG P et al. CCR9 Promotes Migration and Invasion of Lung Adenocarcinoma Cancer Stem Cells. Int J Med Sci 2020; 17: 912-920. https:// doi.org/10.7150/ijms.40864 
[29] ZHANG Z, XIAO Y, ZHAO J, CHEN M, XU Y et al. Relationship between circulating tumour cell count and prognosis following chemotherapy in patients with advanced non-small-cell lung cancer. Respirology 2016; 21: 519-525. https://doi.org/10.1111/resp.12696

[30] HU B, TIAN X, LI Y, LIU Y, YANG T et al. Epithelial-mesenchymal transition may be involved in the immune evasion of circulating gastric tumor cells via downregulation of ULBP1. Cancer Med 2020; 9: 2686-2697. https://doi.org/10.1002/ cam4.2871

[31] AGULNIK M, EPSTEIN JB. Nasopharyngeal carcinoma: current management, future directions and dental implications. Oral Oncol 2008; 44: 617-627. https://doi. org/10.1016/j.oraloncology.2007.08.003

[32] ZHANG L, RIETHDORF S, WU G, WANG T, YANG K et al. Meta-analysis of the prognostic value of circulating tumor cells in breast cancer. Clin Cancer Res 2012; 18: 5701-5710. https://doi.org/10.1158/1078-0432.CCR-12-1587

[33] FRIEDLANDER TW, NGO VT, DONG H, PREMASEKHARAN G, WEINBERG V et al. Detection and characterization of invasive circulating tumor cells derived from men with metastatic castration-resistant prostate cancer. Int J Cancer 2014; 134: 2284-2293. https://doi.org/10.1002/ijc.28561

[34] ZHAO XH, WANG ZR, CHEN CL, DI L, BI ZF et al. Molecular detection of epithelial-mesenchymal transition markers in circulating tumor cells from pancreatic cancer patients: Potential role in clinical practice. World J Gastroenterol 2019; 25: 138-150. https://doi.org/10.3748/wjg.v25.i1.138

[35] NING N, ZHAN T, ZHANG Y, CHEN Q, FENG $\mathrm{F}$ et al. Improvement of specific detection of circulating tumor cells using combined CD45 staining and fluorescence in situ hybridization. Clin Chim Acta 2014; 433: 69-75. https://doi. org/10.1016/j.cca.2014.02.019

[36] NANOU A, MILLER MC, ZEUNE LL, DE WIT S, PUNT CJA et al. Tumour-derived extracellular vesicles in blood of metastatic cancer patients associate with overall survival. Br J Cancer 2020; 122: 801-811. https://doi.org/10.1038/ s41416-019-0726-9

[37] YANG Z, WANG J, ZHANG Z, TANG F. Epstein-Barr Virus-Encoded Products Promote Circulating Tumor Cell Generation: A Novel Mechanism of Nasopharyngeal Carcinoma Metastasis. Onco Targets Ther 2019; 12: 11793-11804. https://doi.org/10.2147/OTT.S235948

[38] QIAN Y, WU Y, YUAN Z, NIU X, HE Y et al. The Frequency of Circulating Tumour Cells and the Correlation with the Clinical Response to Standard Chemoradiotherapy in Locally Advanced Nasopharyngeal Carcinoma: A Prospective Study. Cancer Manag Res 2019; 11: 10187-10193. https:// doi.org/10.2147/CMAR.S222916

[39] Chen Z, Xu L, Xu X, Yuan C. The clinical value of detecting circulating tumour cells in the peripheral blood of nasopharyngeal carcinoma patients. Oncol Lett 2018; 15: 6283-6290. https://doi.org/10.3892/ol.2018.8155
[40] LIU X, ZHANG Z, ZHANG B, ZHENG Y, ZHENG C et al. Circulating tumor cells detection in neuroblastoma patients by EpCAM-independent enrichment and immunostainingfluorescence in situ hybridization. EBioMedicine 2018; 35: 244-250. https://doi.org/10.1016/j.ebiom.2018.08.005

[41] GAO Y, ZHU Y, ZHANG Z, ZHANG C, HUANG X et al. Clinical significance of pancreatic circulating tumor cells using combined negative enrichment and immunostainingfluorescence in situ hybridization. J Exp Clin Cancer Res 2016; 35: 66. https://doi.org/10.1186/s13046-016-0340-0

[42] LIU H, SUN B, WANG S, LIU C, LU Y et al. Circulating Tumor Cells as a Biomarker in Pancreatic Ductal Adenocarcinoma. Cell Physiol Biochem 2017; 42: 373-382. https://doi. org/10.1159/000477481

[43] ASANTE DB, CALAPRE L, ZIMAN M, MENIAWY TM, GRAY ES. Liquid biopsy in ovarian cancer using circulating tumor DNA and cells: Ready for prime time? Cancer Lett 2020; 468: 59-71. https://doi.org/10.1016/j.canlet.2019.10.014

[44] NEGIN BP, COHEN SJ. Circulating tumor cells in colorectal cancer: past, present, and future challenges. Curr Treat Options Oncol 2010; 11: 1-13. https://doi.org/10.1007/s11864010-0115-3

[45] SUN S, QIU XS. Cancer stem cells and tumor metastasis. J Cancer Res Ther 2013; 9: S150-152. https://doi. org/10.4103/0973-1482.122510

[46] Clarke, M.F., et al. Cancer stem cells--perspectives on current status and future directions: AACR Workshop on cancer stem cells. Cancer Res 2006; 66: 9339-9344. https://doi. org/10.1158/0008-5472.CAN-06-3126

[47] PAPADAKI MA, STOUPIS G, THEODOROPOULOS PA, MAVROUDIS D, GEORGOULIAS V et al. Circulating Tumor Cells with Stemness and Epithelial-to-Mesenchymal Transition Features Are Chemoresistant and Predictive of Poor Outcome in Metastatic Breast Cancer. Mol Cancer Ther 2019; 18: 437-447. https://doi.org/10.1158/1535-7163.MCT18-0584

[48] PEREIRA-VEIGA T, MARTÍNEZ-FERNÁNDEZ M, ABUIN C, PIÑEIRO R, CEBEY V et al. CTCs Expression Profiling for Advanced Breast Cancer Monitoring. Cancers (Basel) 2019; 11: 1941. https://doi.org/10.3390/cancers11121941

[49] AKTAS B, TEWES M, FEHM T, HAUCH S, KIMMIG R et al. Stem cell and epithelial-mesenchymal transition markers are frequently overexpressed in circulating tumor cells of metastatic breast cancer patients. Breast Cancer Res 2009; 11: R46. https://doi.org/10.1186/bcr2333 